\title{
Assessment of the interlaminar behaviour of a carbon fabric reinforced thermoplastic lapshear specimen under quasi-static and tension-tension fatigue loading
}

\author{
I. De Baere, W. Van Paepegem and J. Degrieck \\ Department of Materials Science and Engineering, Faculty of Engineering and Architecture, \\ Ghent University. Technologiepark-Zwijnaarde 903, B-9052 Zwijnaarde, Belgium.
}

E-mail: Ives.DeBaere@UGent.be

\begin{abstract}
Although fusion bonded joints have already been extensively studied, they are only rarely compared to benchmark specimens with the same interlaminar behaviour of the composite material being joined, especially for the lapshear geometry. Even more, an extensive study of these benchmarks under quasi-static and fatigue loading conditions as almost never considered.

In this manuscript, a method of producing such benchmark lapshear specimens is presented for a hot pressed carbon fabric reinforced thermoplastic. The mechanical behaviour of these specimens is then assessed using quasi-static, hysteresis and tensiontension fatigue experiments.

It could be concluded that the considered approach worked well for this material and reproducible results and values were found. With respect to the material, no crack growth was visible during the quasi-static experiments, except near the very end of life, whereas significant crack growth was present during fatigue experiments.
\end{abstract}

\section{Introduction}

The study presented here fits within a broader research project on the mechanical behaviour of fusion bonded joints between the material considered for this manuscript, which is a carbon fibre 5-harness satin weave reinforced polyphenylene sulphide (PPS).

A first paper was already published on the optimization of the welding parameters of this infrared welding [1], where the results of single lapshear experiments were used for the assessment of quality and reproducibility of the joints. A second study was conducted in order to determine the interlaminar behaviour under pure mode I, using the double cantilever beam test, and pure mode II, using the end notch flexure test, loading conditions [2]; values for $G_{I}$ and $G_{I I}$ were also determined, both for initiation and propagation. This study was done in order to obtain a benchmark for the welded joints to be compared with.

Prior to going to fatigue lapshear experiments on the welded joints, it was decided that it would be useful to again have a benchmark for the lapshear behaviour of the base material. Therefore, the emphasis of this manuscript lies on determining the mechanical behaviour of the carbon PPS under study for a lapshear specimen, where the shear loaded overlap has the exact same properties of the standard hot pressed plates, as for these, the production process has been optimised and should therefore yield the best interlaminar behaviour achievable. Although different fusion bonding processes have already been extensively studied, as illustrated in various review articles [3, 4, 5], the comparison between a benchmark and the welds is only rarely considered $[6,7,8]$. For these studies, benchmark or reference specimens are mentioned, but not much detail is 
mentioned. Usually, only lapshear strength values are listed in a table, but detailed information and images on the production method are not given. Furthermore, only the quasi-static behaviour is considered.

To obtain a lapshear geometry with the optimal properties, some possibilities are already considered in the mentioned literature.

Developing a hot pressing mould for this geometry, which was considered in [6] not only is difficult and expensive, it would also mean that a different mould is needed for other material types, or other overlap lengths. In [7], an autoclaved reference is mentioned, but no further details on the process, for instance on how to obtain straight edges on the overlap. In [8], a plate of sufficient thickness is considered, after which the unnecessary material is removed by machining and grinded, but again, no further details, for instance on surface and edge quality, or the occurrence of delaminations due to the machining are given. The method presented in this paper also uses the principle of removing excess material, but with only limited machining.

Determining the interlaminar behaviour for a specific composite using lapshear specimens is in fact not new, such an approach is sometimes considered to compare adhesively bonded joints with co-cured joints [9, 10, 11, 12]; the latter essentially having the same interlaminar properties as the base plates. Also for Z-pin reinforced composites, the reinforcing effect of the Z-pins on the shear behaviour of the joint is sometimes assessed by comparing co-cured joints with Z-pin reinforced co-cured joints [13, 14, 15, 16, 17, 18], but most authors consider Mode I or Mode II testing; the lapshear geometry is only used in $[17,18]$. However, the previously mentioned studies all work on fibre reinforced epoxies, made with pre-pregs.

To the authors' best knowledge, an extensive study of the benchmark lap shear experiments both under quasi-static and tension-tension fatigue, has yet not been published or assessed in open literature for continuous fibre reinforced thermoplastics.

The results within this paper, together with the Mode I and Mode II results, published in [2] should provide an interesting benchmark for comparing (fatigue) data from fusion bonded joints between the carbon reinforced PPS, either by the already mentioned infrared welding, but also for other processes such as for example ultrasonic, induction welding or resistance welding [19].

The next paragraph illustrates the used material and methods, after which the single lapshear experiments are discussed. Finally, some conclusions are drawn.

\section{Materials and Methods}

\subsection{Composite Material}

The material under study was a carbon fibre-reinforced polyphenylene sulphide (PPS), called CETEX. This material is supplied to us by Ten Cate. The fibre type is the carbon fibre T300J 3K and the weaving pattern is a 5-harness satin weave with a mass per surface unit of $286 \mathrm{~g} / \mathrm{m}^{2}$. The 5-harness satin weave is a fabric with high strength in both directions and excellent bending properties.

The carbon PPS plates were hot pressed at 10 bars and $310{ }^{\circ} \mathrm{C}$; only one stacking sequence was used for this study, namely $\left[\left(0^{\circ}, 90^{\circ}\right)_{4 s}\right]_{s}$ where $\left(0^{\circ}, 90^{\circ}\right)$ represents one layer of fabric. The choice for this stacking sequence was driven by the fact that the experiments in this manuscript will serve as benchmark for the welded specimens, which also have this stacking sequence in their welded overlap [1]. 
The in-plane elastic properties of the individual carbon PPS lamina were determined by the dynamic modulus identification method as described in [20], the tensile strength properties of the lamina were determined at the Technical University of Delft. Both sets of values are listed in Table 1.

Table 1 In-plane elastic and tensile strength properties of the individual carbon/PPS lamina

\begin{tabular}{cccccc}
\hline $\mathrm{E}_{11}$ & 56.0 & $\mathrm{GPa}$ & $\mathrm{X}_{\mathrm{T}}$ & 734.0 & $\mathrm{Mpa}$ \\
$\mathrm{E}_{22}$ & 57.0 & $\mathrm{Gpa}$ & $\varepsilon_{11}{ }^{\text {ult }}$ & 0.011 & - \\
$\mathrm{v}_{12}$ & 0.033 & - & $\mathrm{Y}_{\mathrm{T}}$ & 754.0 & $\mathrm{Mpa}$ \\
$\mathrm{G}_{12}$ & 4.175 & $\mathrm{Gpa}$ & $\varepsilon_{22}$ ult & 0.013 & - \\
& & & $\mathrm{S}_{\mathrm{T}}$ & 110.0 & $\mathrm{Mpa}$ \\
\hline
\end{tabular}

The desired geometry of the single lapshear specimen is illustrated in Figure 1 and is is chosen according to the ASTM D5868-01 'Standard Test Method for Lap Shear Adhesion for Fiber Reinforced Plastic Bonding', which was also considered for [1]; the width of the specimen is $25 \mathrm{~mm}$.

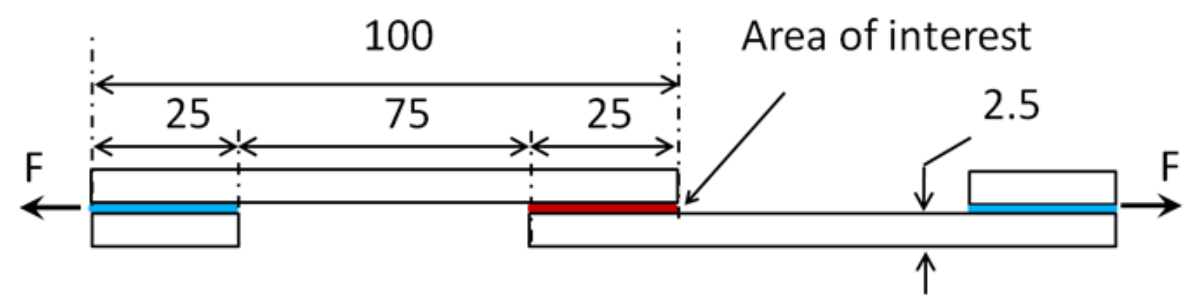

Figure 1 Single-lapshear geometry; dimensions in $\mathrm{mm}$.

To obtain such a geometry using the hot pressing process, a very specific and expensive closed mould would be necessary, which would then only be suitable for one specific overlap length. As this was not available, a different way of achieving this geometry was examined, which is elaborated on in the next paragraph.

\section{2. $\quad$ Test specimen preparation}

The idea was to produce a larger plate with the same stacking sequence of the welded overlaps in [1], and then to trim away all unwanted parts to obtain the desired lapshear geometry. By doing so, the overlap of the lapshear specimen is produced using the optimal process parameters for the standard plates. However, as it is not the purpose to induce a significant amount of damage by milling away all unnecessary material, thus corrupting the experimental data, a kapton film of 50 micron was carefully inserted on strategic places, so that four cuts with a diamond disc suffice to obtain the lapshear geometry; Teflon film was not an option, because the processing temperature of the carbon-PPS exceeds the maximum service temperature of Teflon films. Figure 2 illustrates this process and Figure 3 shows the placing of the kapton film in the central plane of the stacking sequence. 

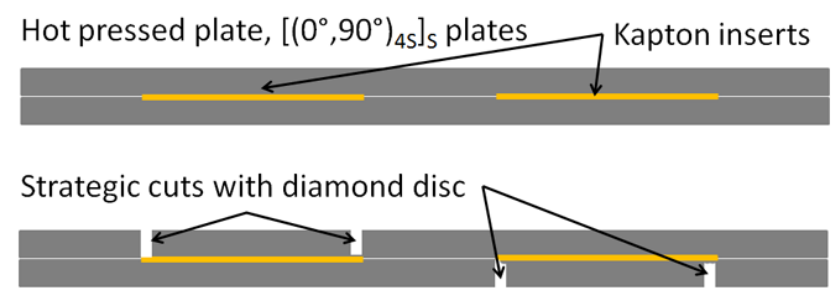

Final lapshear specimen

Figure 2 Illustration of the cutting of the single-lapshear geometry.

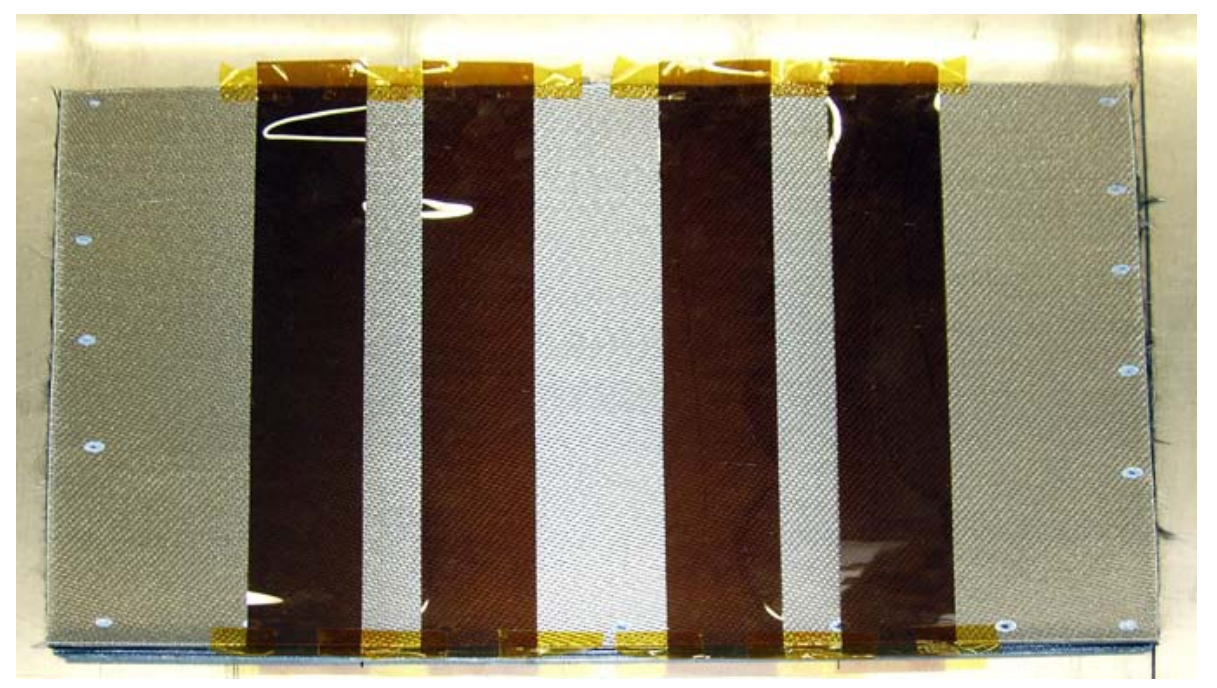

Figure 3 Illustration of the central plane of the 16-layer stacking sequence: position of the kapton film

After hot pressing of the plate and cutting away the rough edges of the plate, the sides were examined using a microscope and the exact position of the kapton film was marked on the plate. Then, the cuts were made, making sure that the depth did not exceed half of the plate; ideally, the cut should be just as deep as the kapton film. Finally, the excess parts are removed.

As already mentioned, milling in composite materials will most likely induce damage, such as delaminations, into the composite. Furthermore, the cut should have the exact depth to have the correct lapshear geometry on the microscopical level (meaning a fairly straight angle), since otherwise unwanted stress concentrations could arise which will influence crack initiation, both under static and fatigue loading conditions [12, 21, 22, $23,24,25,26]$.

However, if the described process is done very carefully, then nice straight angles can be obtained and no delaminations are induced, although it should be mentioned that with the presented method and for this material, no delaminations arose due to specimen preparation. Figure 4 illustrates the straight edge of the overlap region of one of the tested specimens. 


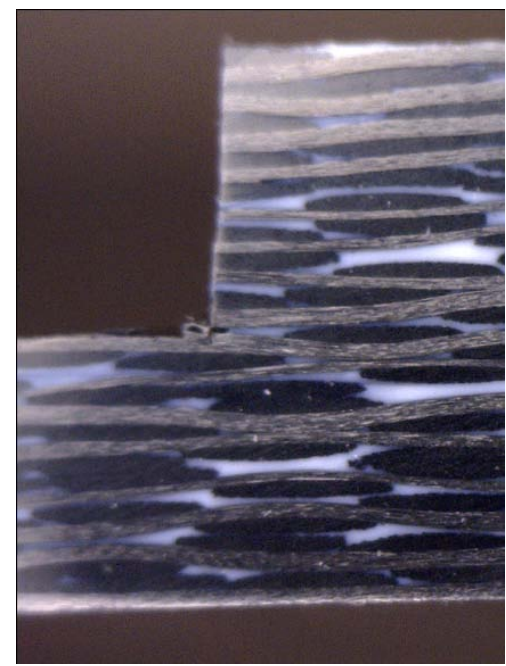

Figure 4 Illustration of the quality and depth of the cut

For all specimens documented in this manuscript, it was first confirmed microscopically that a nice cut at the correct depth was achieved and that no delaminations due to the cutting were present. The length of the overlap was $25.0 \pm 0.5 \mathrm{~mm}$ for all specimens.

\subsection{Equipment}

All tensile tests were performed on a servo-hydraulic INSTRON 8801 tensile testing machine with a FastTrack 8800 digital controller and a load cell of $\pm 100 \mathrm{kN}$. The quasistatic tests were displacement-controlled at a displacement speed of $0.5 \mathrm{~mm} / \mathrm{min}$, whereas the fatigue experiments were done in load-control.

For the registration of the tensile data, a combination of a National Instruments USB 6251 data acquisition card and the SCB-68 pin shielded connector were used. The load $\mathrm{F}$ and displacement $\delta$, given by the FastTrack controller were sampled on the same time basis.

\section{Experiments and Discussion}

For all experiments described in this manuscript, force and displacement where registered. To be able to compare the results amongst each other, the averaged shear stress $\tau$, equal to the force divided by the total, original (so not taking possible crack growth into account) overlap surface, is calculated. As the displacement of the tensile machine is used to characterise deformation, every specimen was mounted in the exact same way in the grips, this to minimise differences in slipping in the grips and to have equal boundary conditions for every test. Indeed, should a specimen be mounted deeper inside the grips, then the bending of the adherends, implicit to the lapshear geometry, would be inhibited more, because of the support of the grips.

\subsection{Quasi-static experiments}

The first concern was of course to verify whether reproducible results were achieved with the proposed method of generating specimens. As such, a large amount of specimens were generated and tested. Since at first, the procedure was not yet optimised, specimen were produced with the cuts too deep, so this provided the opportunity to assess the influence of this geometrical error on the results. It could be concluded that in this case, reproducibility was very low, there was a large scatter on the failure load and also the damage behaviour was different. In some cases, the crack still originated and propagated in the centre plane of the specimen, where it should 
propagate. In this case, the achieved strength was near the level of the good specimens, but in most cases, the crack initiated at the bottom of the cut and propagated out of the centre plane, causing a significantly lower failure load. Also, both effects occurred randomly.

Figure 5 illustrates a few of the results from the specimens with the correct geometry and as can be seen, reproducible results are obtained. There is a little scatter on the stiffness of the lapshear joint, but this is due to the small differences in overlap, as was validated by finite element modelling, which is not discussed here. An averaged failure load of 17.7 Mpa \pm 0.4 Mpa was obtained from all experiments. For clarity’s sake, the different curves are given an offset along the displacement-axis.

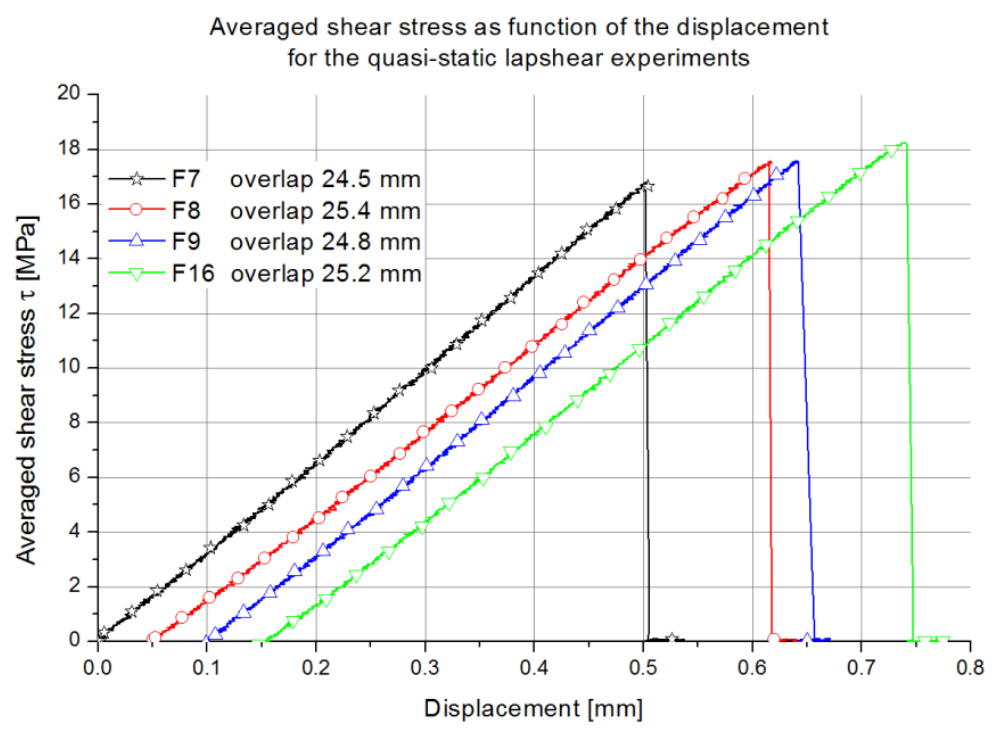

Figure 5 Results for the quasi-static lapshear experiments

In $[6,8,7]$, the benchmark usually yielded higher failure loads than the fusion bonded samples, but for this material, the failure load is around 7 Mpa lower than for the welded joints in the previous study [1]. Thus, the question arises what the origin of this effect may be. As such, a number of specimens where polished and with a travelling microscope, the edge of the overlap was observed to assess the origin and propagation of the crack. Figure 6 illustrates the pictures taken during the experiment on sample F16, pictures were taken every $500 \mathrm{~N}$ and at failure, but only the significant ones are shown here. Besides bending of the specimen, nothing was really noticeable until $9 \mathrm{kN}$ was reached. Between $9 \mathrm{kN}$ (14.3 MPa averaged shear stress) and $10 \mathrm{kN}$ ( $\tau=15,9 \mathrm{MPa}$ ) a small change in colour (whitening of the area) could be distinguished in the corner of the lapshear, hinting that a crack tip was initiating. This crack tip could be distinguished in the picture of $10.5 \mathrm{kN}$ ( $\tau=16.7 \mathrm{MPa}$ )(Figure 6 (a)). At $11 \mathrm{kN}(\tau=17,5 \mathrm{MPa}$ ), this crack is more clearly visible and has a length of about $0.6 \mathrm{~mm}$ at the polished side. 100 $\mathrm{N}$ later, this resulted in final failure of the specimen. Similar observations were made for other specimens. 


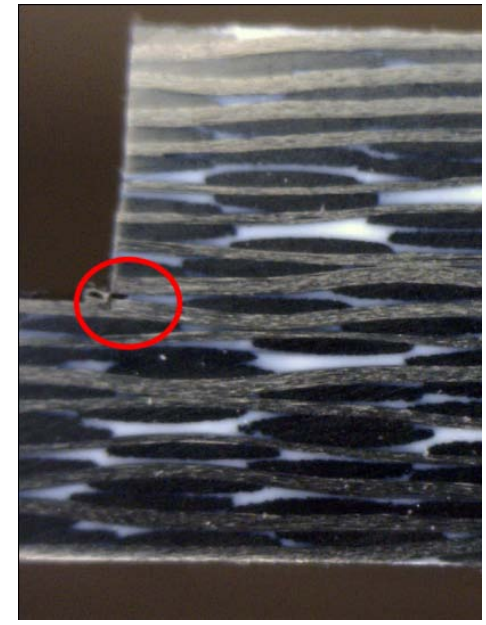

(a) At $10.5 \mathrm{kN}$

$\tau=16.7 \mathrm{MPa}$

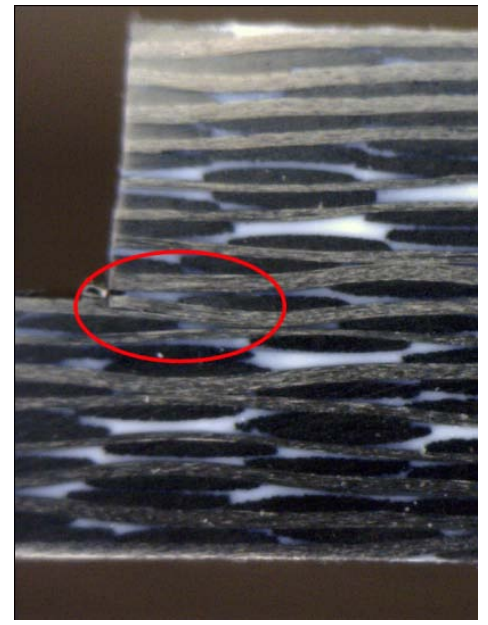

(b) At $11 \mathrm{kN}$

$\tau=17.5 \mathrm{MPa}$

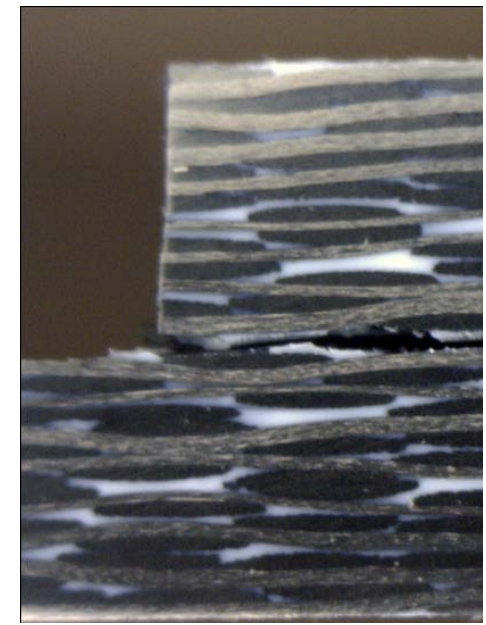

(c) Final failure at $11.1 \mathrm{kN}$ $\tau=17,6 \mathrm{MPa}$

Figure 6 Microscopic images of a quasi-static lapshear test.

As such, it can be concluded that there is virtually no crack growth present before final failure. For the welded samples, crack growth could clearly be distinguished. This, together with the fact that for these benchmark specimens, there is a lot less PPS in the bond area compared to the welded joints, most likely explains the lower failure loads which are achieved here.

\subsection{Quasi-static hysteresis test.}

Given the fact that almost no crack growth is present during quasi-static testing, it seemed interesting to do an intermediate type of test before going to fatigue loads, namely quasi-static testing with increasing maximum load level, and this until failure of the specimen. Similar to the quasi-static tests till failure, the experiments were done displacement-controlled with $0.5 \mathrm{~mm} / \mathrm{min}$ loading speed. The first maximum load was determined at $5 \mathrm{kN}$ to have some reserve with respect to the $9 \mathrm{kN}$ where the first signs of crack initiation appeared during quasi-static testing. Every next maximum was $1 \mathrm{kN}$ higher and microscopic pictures were taken both at the maximum load and after unloading of each cycle of the polished side of the specimen.

Figure 7 illustrates the experimental results of such a test, this specimen failed just before the maximum level of $10 \mathrm{kN}$ was reached. As can be seen from these results, there is a small permanent displacement after the first cycle, but this is due to slippage in the grips. Should crack growth occur, then the slope of the force displacement curve should decrease, but as can be noticed from Figure 7, this is not really the case. The microscopic observation, which was done during the test, revealed the same. On the polished side, there was no crack growth visible, except near the very end of the test, similar to the first test case, and brittle failure occurred in the central plane of the overlap. 


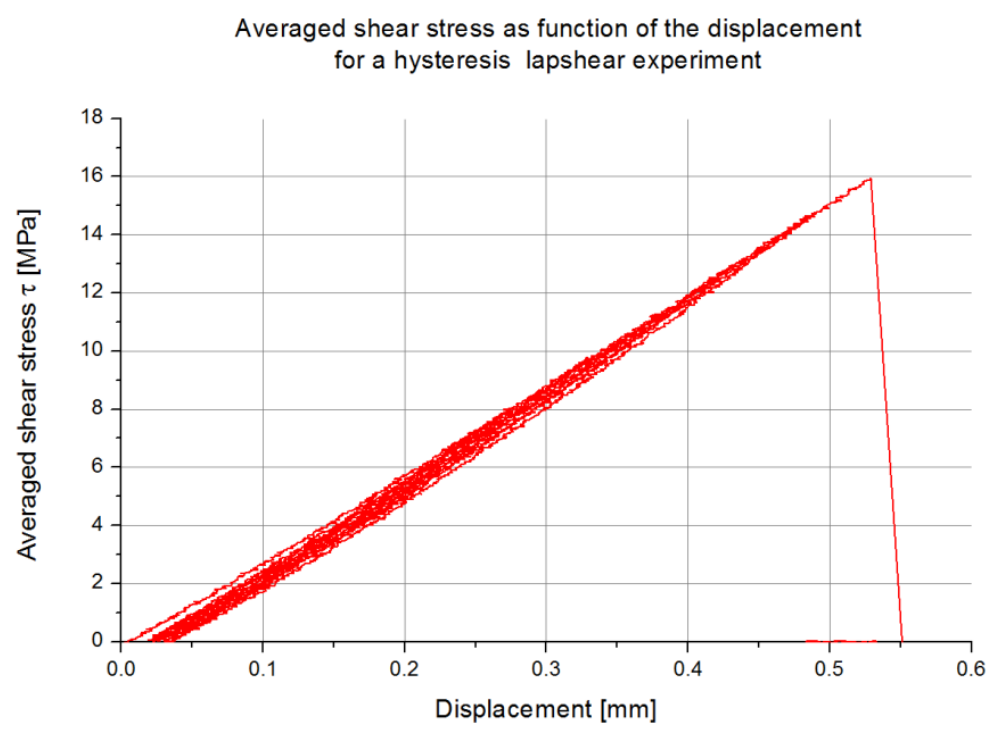

Figure 7 Results for a quasi-static hysteresis lapshear experiment; max load starting at $5 \mathrm{kN}$ and increasing with $1 \mathrm{kN}$ for every cycle.

\subsection{Tension-tension fatigue experiments}

Finally, fatigue experiments were performed. As previously mentioned, all tests were done in load control and to avoid buckling, the minimum load was set at $0.2 \mathrm{kN}$. The maximum load was chosen as a percentage of the average quasi-static failure load and to verify whether a frequency dependency was present, tests were done both at $2 \mathrm{~Hz}$ and $5 \mathrm{~Hz}$ loading frequency. To observe what is happening during the fatigue, every five minutes, four fatigue cycles were registered and the minimum, maximum and mean value of the signals was stored.

Figure 8 gives an overview of the experiments and it can be noted that the scatter is quite low for these results. Furthermore, there is no frequency dependency, contrary to what was found in [27], where the loading frequency had an influence on the fatigue life of the same carbon PPS under study, but for uni-axial tension-tension fatigue.

$\mathrm{S}-\mathrm{N}$ curve for the lapshear tension - tension fatigue

$\star$ Static Failure load $\bullet 2 \mathrm{~Hz}$ loading frequency $\Delta 5 \mathrm{~Hz}$ loading frequency

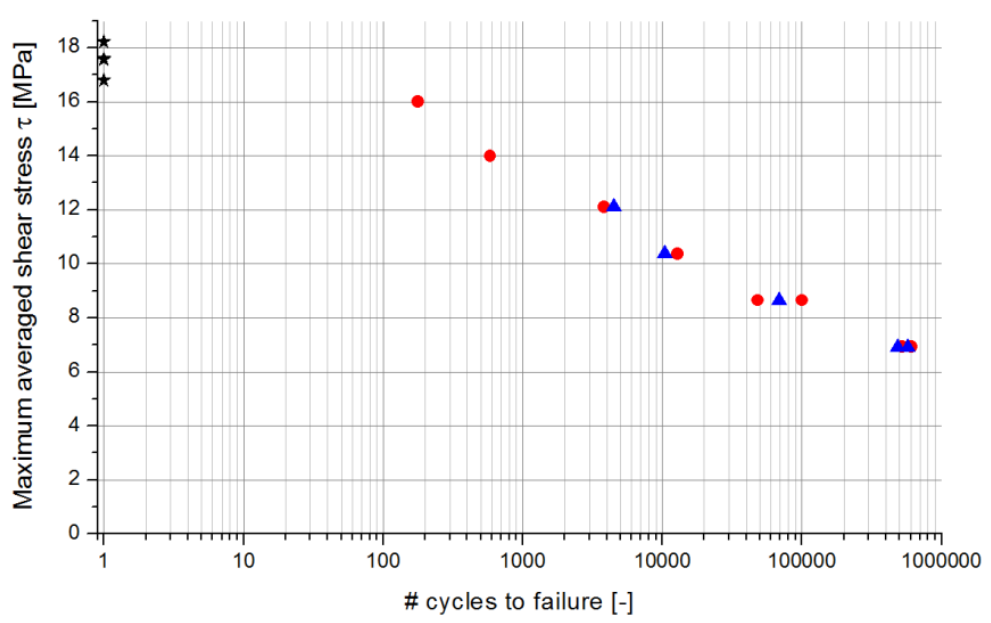

Figure 8 Overview of the maximum applied averaged shear stress as function of the number of cycles for the fatigue experiments.

To have a first idea of what is happening during the fatigue life, the displacement of the specimen is observed using the maximum, minimum and mean values of the 
measurement. As the tests were done in load control, an idea on possible permanent elongation, as well as stiffness degradation can be given. Figure 9 illustrates the evolution of the displacement for one of the experiments. It should be mentioned that a similar behaviour was found for all experiments, regardless the maximum load level and the loading frequency.

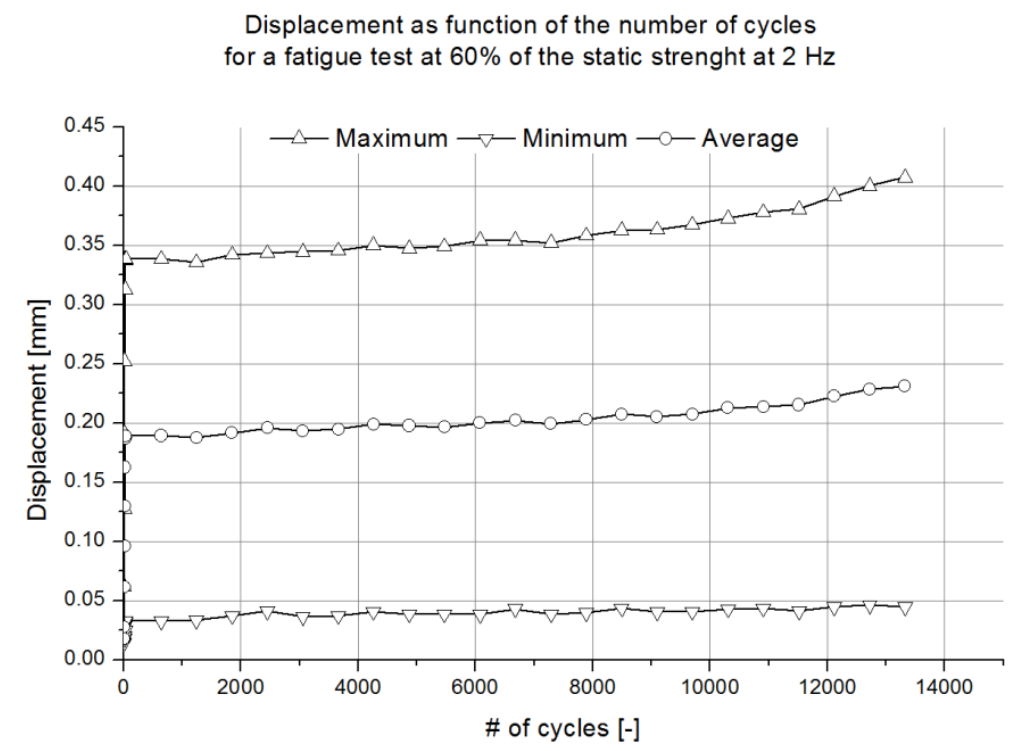

Figure 9 Evolution of the maximum, minimum and average value of the displacement for a $2 \mathrm{~Hz}$ fatigue test at $60 \%$ of the quasi-static strength $\left(\tau^{\max }=10.6 \mathrm{MPa}\right)$.

From these evolutions, two important conclusions can be drawn. As the minimum of the displacement does not increase, there is no permanent deformation. Given the low uniaxial load levels, no permanent deformation of the adherends was expected [27, 28], but this means that there is virtually no permanent deformation of the overlap area under shear loads. A little sliding of the specimen in the grips is present, as can be seen at the beginning of the test since the displacement starts at $0 \mathrm{~mm}$, but increases slightly.

Second, the difference between the maximum and the minimum displacement increases throughout the experiment. This means that the longitudinal stiffness of the specimen decreases and the rate of decrease, increases with increasing number of cycles. This stiffness decrease suggests crack growth during fatigue life.

To have an idea of the crack growth, again polished samples were tested and the sides were observed using a travelling microscope. To have an idea of the longitudinal stiffness, every x number of cycles, a quasi-static experiment was done, similar to those in section 3.1 and microscopic pictures were taken during these static tests. Figure 10 shows the results for the intermediate quasi-static experiment for such a test, which was done till $50 \%$ of the maximum average shear stress and at $2 \mathrm{~Hz}$. For clarity, only the loading part of the curve is plotted, but there was no hysteresis present for the entire loading cycle. Also here, it can be seen that there is virtually no permanent elongation, only small slippage occurs during the first test. Then, the slope does not change significantly during the first 20000 cycles, but it can clearly be noted that the curve for 30000 and certainly for 40000 has a lower slope. This specimen failed after 48229 cycles. 


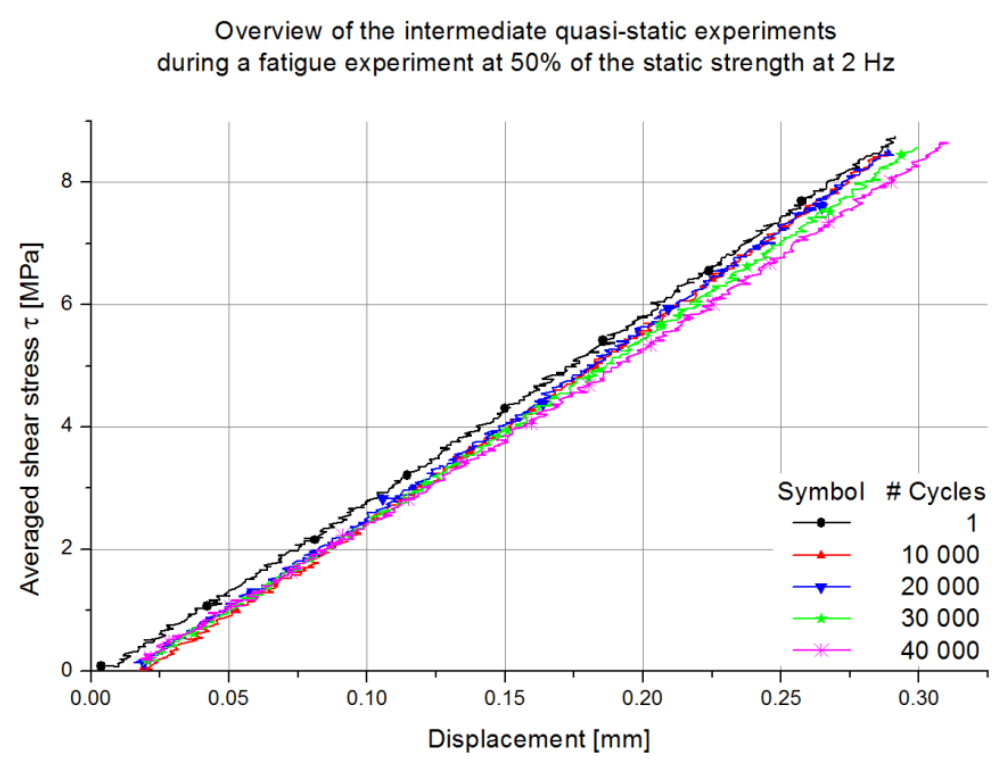

Figure 10 Average shear stress as function of the displacement for the intermediate quasi-static test during a fatigue test.

Figure 11 illustrates the microscopic pictures, taken during the intermediate quasi-static tests, at maximum load of the static test, which of course did not exceed the maximum load during the fatigue experiment so no extra damage is generated. As such, the crack opens up due to the inherent bending and the crack is more easily visualised. On the images, the actual crack, meaning where there is no longer contact between the crack fronts, is highlighted with a red line. When observing the images more closely, a small area in front of the crack tip again showed the whitening of the colour (similar to what was seen during the quasi-static test till failure, described earlier), meaning that damage processes occur in front of the crack tip.

For pictures I and (d), it can be seen that the crack initially follows the warp yarns $\left(0^{\circ}\right)$ of the layer I, but then jumps again to the mid-plane (d). At final failure, the crack indeed propagated in the central plane of the specimen; occasionally, some of the weft yarns $\left(90^{\circ}\right)$ were pulled out.

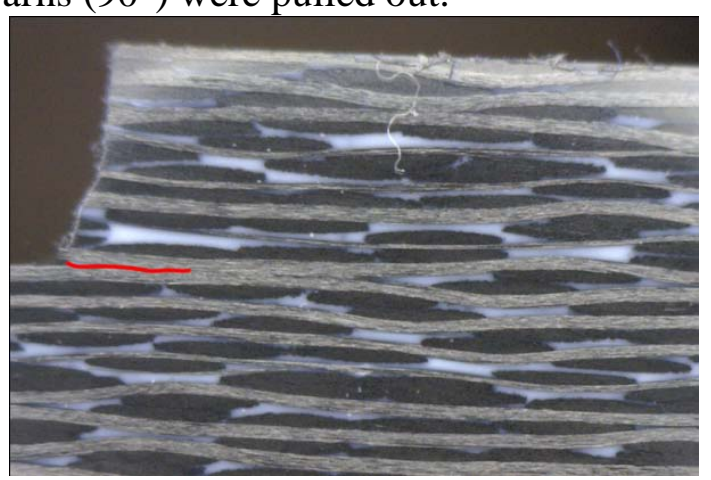

(a) After 10000 cycles

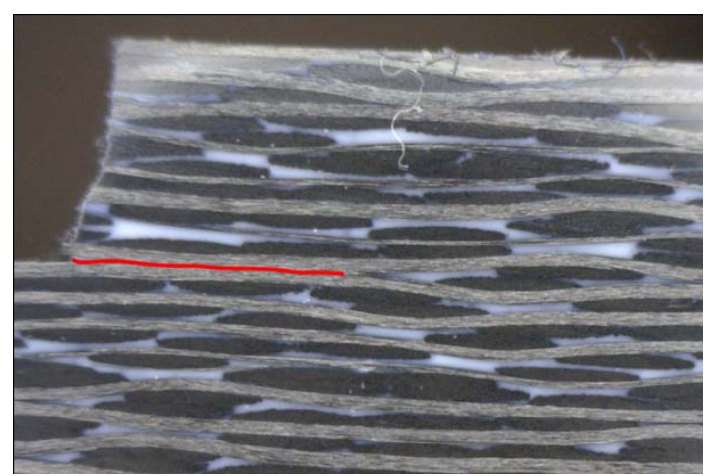

(b) After 20000 cycles 


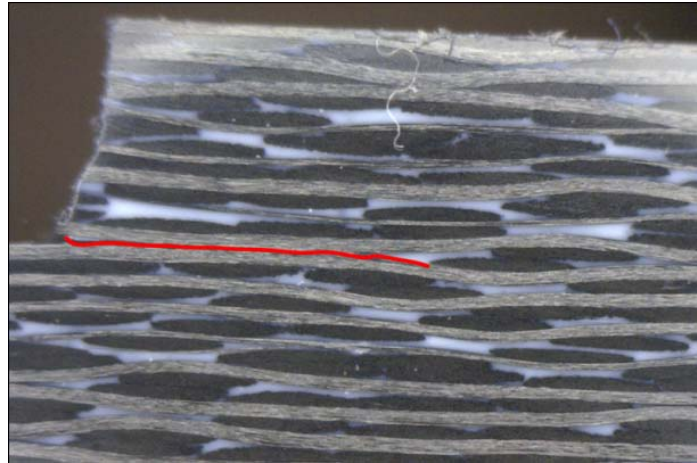

I After 30000 cycles

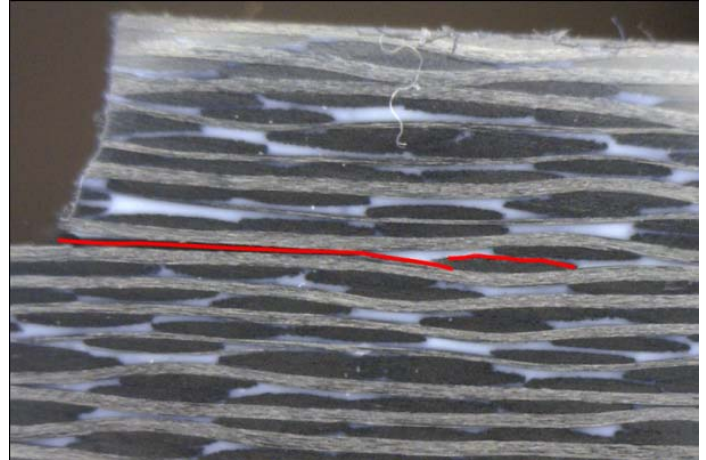

(d) After 40000 cycles

Figure 11 Overview of microscopic assessment of the crack growth during a fatigue experiment; pictures taken at maximum load.

As previously mentioned, given the fact that the fatigue tests are done in load control, the difference between maximum and minimum displacement yield information on the overall stiffness of the specimen. If this is visualised in another way, however, an interesting phenomenon arises. Consider the relative change in stiffness $k_{\text {rel }}{ }^{N}$ after a certain number of cycles $\mathrm{N}$, calculated by Equation (1):

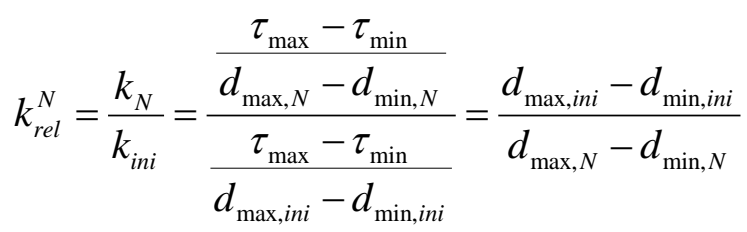

Where $\tau_{\max }-\tau_{\min }=$ average shear stress amplitude, which is constant (load control)

$\mathrm{d}_{(\min / \max ), \mathrm{N}}=$ maximum or minimum displacement after $\mathrm{N}$ cycles

$\mathrm{d}_{(\min / \max ), \text { ini }}=$ maximum or minimum displacement just after run-in of the test

By using the displacement amplitude after the run-in of the test, the effect of slippage in and further tightening of the grips is ruled out. If this parameter is plotted against the relative time $N / N_{f}$ with $N_{f}$ the number of cycles till failure, then this yields Figure 12, where a representative of every load level and frequency is plotted. It was verified for all tests that a similar overlapping curve was found; only one is plotted here for clarity's sake.

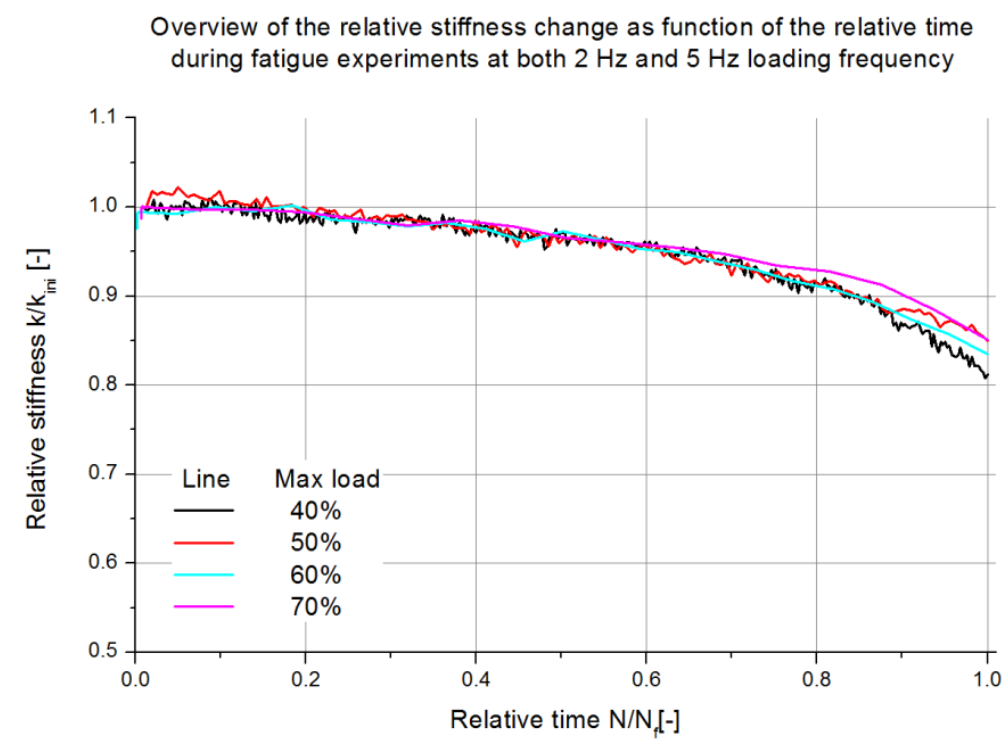

Figure 12 Illustration of the relative decrease in slope as function of relative fatigue life. 
It is important to note that almost exactly the same curve is achieved, regardless of the loading frequency or maximum load level. As there was no influence of the frequency on the fatigue life, it is quite fair to assume that the frequency again has no influence in this case. The fact that the load level also has no influence, is more surprising, given the fact how $k_{\text {rel }}{ }^{N}$ was determined. This can be understood by observing Figure 13. Because of the implicit bending of the lapshear adherends, the force or shear does not increase linearly with the displacement, but it shows an increasing slope (original loading curve). As only the maximum and minimum value of the curve are considered in Equation (1), rather than the entire evolution, which would prove a lot more cumbersome, results from different load levels (level1 vs. level2) are compared to different initial slopes (slope 1 vs. slope 2). It should be mentioned that the 'original loading curve' in Figure 13 was artificially generated to illustrate the principle; for real experiments, the different is a lot smaller, but nevertheless present.

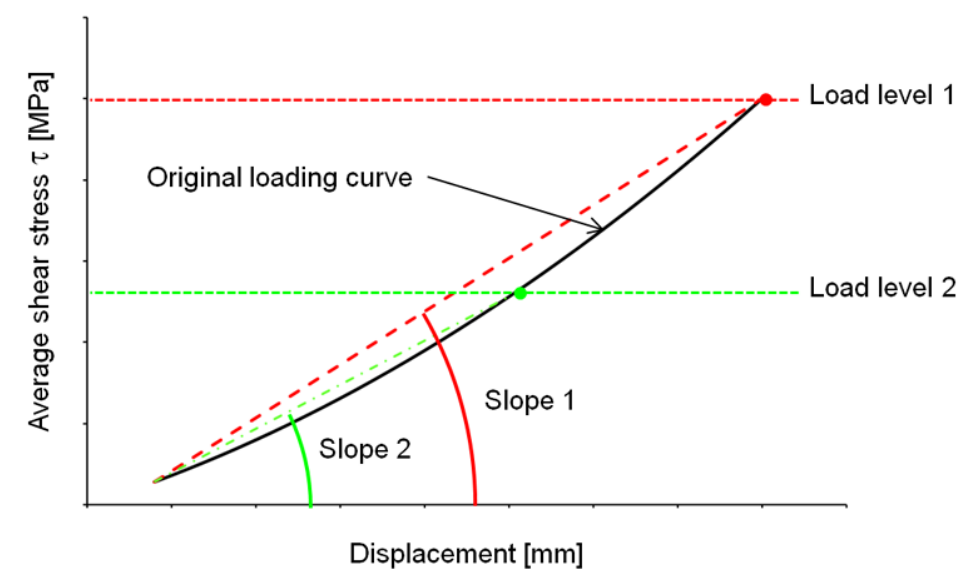

Figure 13 Illustration of the different slopes for different maximum load regimes.

The fact that Figure 12 shows some sort of 'fatigue master curve', is in fact not that complicated to explain, by using Paris' law for crack growth (Equation (2) [29]), which also represents the crack growth behaviour during fatigue life. As is well known, this equation yields the crack growth per fatigue cycle as a function of the stress intensity factor or also of the strain energy release rate at the crack tip. Hence, a higher stress intensity results in a larger crack growth and thus a shorter fatigue life. The relation with the results shown in Figure 12 is that the (relative) stiffness of the specimen is used. Of course, the stiffness depends on the crack length and the longer the crack, the lower the stiffness, although it is not a linear relation. This relation was also verified using finite element simulations.

With a the crack length

$$
\frac{d a}{d N}=C \Delta K^{m}
$$

$\mathrm{N}$ the number of cycles

$\mathrm{C}, \mathrm{m}, \mathrm{C}_{\mathrm{P}}$, n empirical constants

$\Delta \mathrm{K}=\mathrm{K}_{\max }-\mathrm{K}_{\min }$ the stress intensity factor range

The main advantage of working with the relative stiffness of the specimen is that there is no need to measure the crack length in order to determine the remaining fatigue life. Only the stiffness of the undamaged specimen at the start of the test and the current 
stiffness and number of cycles suffices to determine where exactly the test is on the master curve and the remaining fatigue life can be estimated.

\section{Conclusions}

In this manuscript, the interlaminar behaviour of a 5 harness carbon fabric reinforced polyphenylene sulphide was examined using lapshear experiments, with a geometry according to the ASTM D5868-01 'Standard Test Method for Lap Shear Adhesion for Fiber Reinforced Plastic Bonding'. This geometry was derived from hot pressed plates, by removing the excess material in order to obtain this geometry, thus yielding a lapshear overlap with the exact same interlaminer properties as standard hot pressed plates. Quasi-static, hysteresis and fatigue loading conditions were considered and the influence on force-displacement relationship, crack growth and fatigue behaviour was observed.

Taking the production method for obtaining the specimens into account, it could be concluded that reproducibility was very high under all three loading conditions. It was found that under quasi-static loading, both till failure and with continuously loading and unloading with increasing maximum load, there was virtually no crack growth and only just before final, brittle failure, a small crack could be distinguished on the polished sides of the specimen. For fatigue loads, however, crack growth could very clearly be seen, even very early in fatigue life. Two loading frequencies were considered, however no significant influence on the behaviour and lifetime could be observed. When plotting the relative stiffness of the entire specimen as a function of the relative fatigue life, a 'master curve' which was the same, regardless of maximum load level or frequency, could be derived. This master curve in fact gives similar information as Paris' law and thus also allows predicting remaining lifetime, but without the need of measuring the crack length.

\section{Acknowledgements}

The authors are highly indebted to the Fund of Scientific Research - Flanders (F.W.O.) for sponsoring this research and to Ten Cate Advanced Composites for supplying the material. Also special thanks to L. Vanden Broecke for his contribution to this work.

\section{References}

[1] De Baere I., Allaer, K., Jacques S., Van Paepegem W. and Degrieck J. Study of the interlaminar behavior of infrared welded joints of carbon fabric reinforced polyphenylene sulphide. Polymer Composites 33 (7) pp1105-1113 (2012)

[2] De Baere I., Jacques S., Van Paepegem W. and Degrieck J. Study of the Mode I and Mode II interlaminar 13ehavior of a carbon fabric reinforced thermoplastic. Polymer Testing, Volume 31, Issue 2, April 2012, Pages 322 - 332

[3] Stavrov D, Bersee HEN. Resistance welding of thermoplastic composites - an overview. COMPOSITES PART A-APPLIED SCIENCE AND MANUFACTURING 36 (1): 39-54 2005

[4] Ageorges C, Ye L, Hou M. Advances in fusion bonding techniques for joining thermoplastic matrix composites: a review. COMPOSITES PART A-APPLIED SCIENCE AND MANUFACTURING 32 (6): 839-857 2001.

[5] Yousefpour A, Hojjati M, Immarigeon JP. Fusion bonding/welding of thermoplastic composites. JOURNAL OF THERMOPLASTIC COMPOSITE MATERIALS 17 (4): 303-341 JUL 2004.

[6] Hou M, Ye L, Mai YW. An experimental study of resistance welding of carbon fibre fabric reinforced polyetherimide (CF fabric PEI) composite material. APPLIED COMPOSITE MATERIALS 6 (1): 35-49 JAN 1999.

[7] W. Suwanwatana, S. Yarlagadda and J.W. Gillespie, Jr. Hysteresis heating based induction bonding of thermoplastic composites. COMPOSITES SCIENCE AND TECHNOLOGY 66 (1112): 1713-1723 SEP 2006. 
[8] Ageorges C, Ye L, Hou M. Experimental investigation of the resistance welding of thermoplastic-matrix composites. Part II: optimum processing window and mechanical performance. COMPOSITES SCIENCE AND TECHNOLOGY 60 (8): 1191-1202 2000.

[9] Song, M.G., J.H. Kweon, J.H. Choi, J.H. Byun, M.H. Song, S.J. Shin, and T.J. Lee, Effect of manufacturing methods on the shear strength of composite single-lap bonded joints. Composite Structures, 2010. 92(9): p. 2194-2202.

[10] Shin, K.C., J.J. Lee, and D.G. Lee, A study on the lap shear strength of a co-cured single lap joint. Journal of Adhesion Science and Technology, 2000. 14(1): p. 123-139.

[11] Lee, S.W., D.G. Lee, and K.S. Jeong, Static and dynamic torque characteristics of composite cocured single lap joint. Journal of Composite Materials, 1997. 31(21): p. 2188-2201.

[12] Zhao, G.H., Q.L. Shu, and B.S. Huang, Effect of Geometry on Stress Distribution of Spew Fillet of Co-cured Composite Single Lap Joint, in Advances in Civil Engineering and Architecture Innovation, Pts 1-6, Q. Yang, et al., Editors. 2012, Trans Tech Publications Ltd: Stafa-Zurich. p. 179-182.

[13] Mouritz, A.P., Review of z-pinned composite laminates. Composites Part a-Applied Science and Manufacturing, 2007. 38(12): p. 2383-2397.

[14] Mouritz, A.P., P. Chang, and M.D. Isa, Z-Pin Composites: Aerospace Structural Design Considerations. Journal of Aerospace Engineering, 2011. 24(4): p. 425-432.

[15] Byrd, L.W. and V. Birman, Effectiveness of z-pins in preventing delamination of co-cured composite joints on the example of a double cantilever test. Composites Part B-Engineering, 2006. 37(4-5): p. 365-378.

[16] Rugg, K.L., B.N. Cox, and R. Massabo, Mixed mode delamination of polymer composite laminates reinforced through the thickness by z-fibers. Composites Part a-Applied Science and Manufacturing, 2002. 33(2): p. 177-190.

[17] Rugg, K.L., B.N. Cox, K.E. Ward, and G.O. Sherrick, Damage mechanisms for angled throughthickness rod reinforcement in carbon-epoxy laminates. Composites Part a-Applied Science and Manufacturing, 1998. 29(12): p. 1603-1613.

[18] Chang, P., A.P. Mouritz, and B.N. Cox, Properties and failure mechanisms of pinned composite lap joints in monotonic and cyclic tension. Composites Science and Technology, 2006. 66(13): p. 2163-2176.

[19] Villegas, I.F., Moser L., Yousefpour A., Mitschang P. and Bersee H.E.N. Process and performance evaluation of ultrasonic, induction and resistance welding of advanced thermoplastic composites. Journal of Thermoplastic Composite Materials. DOI: 10.1177/0892705712456031

[20] De Baere I., Van Paepegem W., Degrieck J., Sol H., Van Hemelrijck D. and Petreli A., Comparison of different identification techniques for measurement of quasi-zero Poisson's ratio of fabric reinforced laminates. Composites A 38 (9) pp. 2047-2054. (2007)

[21] Comer, A.J., K.B. Katnam, W.F. Stanley, and T.M. Young, Characterising the behaviour of composite single lap bonded joints using digital image correlation. International Journal of Adhesion and Adhesives, 2013. 40: p. 215-223.

[22] Quaresimin M, Ricotta M. Stress intensity factors and strain energy release rates in single lap bonded joints in composite materials. COMPOSITES SCIENCE AND TECHNOLOGY 66 (5): 647-656 Sp. Iss. SI, MAY 2006.

[23] Ribeiro, F.L., L. Borges, and J.R.M. d'Almeida, Numerical stress analysis of carbon-fibrereinforced epoxy composite single-lap joints. International Journal of Adhesion and Adhesives, 2011. 31(5): p. 331-337.

[24] Chen, Z., R.D. Adams, and L.F.M. da Silva, Prediction of crack initiation and propagation of adhesive lap joints using an energy failure criterion. Engineering Fracture Mechanics, 2011. 78(6): p. 990-1007.

[25] Meneghetti, G., M. Quaresimin, and M. Ricotta, Influence of the interface ply orientation on the fatigue behaviour of bonded joints in composite materials. International Journal of Fatigue, 2010. 32(1): p. 82-93.

[26] Wang, Z.Y., L. Wang, W. Guo, H. Deng, J.W. Tong, and F. Aymerich, An investigation on 
strain/stress distribution around the overlap end of laminated composite single-lap joints. Composite Structures, 2009. 89(4): p. 589-595.

[27] De Baere I., Van Paepegem W. Hochard C. and Degrieck J On the tension-tension fatigue behaviour of a carbon reinforced thermoplastic part II: A dumbbell-shaped specimen.

Polymer Testing, Volume 30, Issue 6, September 2011, Pages 663-672

[28] De Baere I., Van Paepegem W. Quaresimin M. and Degrieck J. On the tension-tension fatigue behaviour of a carbon reinforced thermoplastic part I: limitations of the ASTM D3039/D3479 standard. Polymer Testing, Volume 30, Issue 6, September 2011, Pages 625-632

[29] Da Silva L.F. and Öchsner A. Modeling of Adhesively Bonded Joints. ISBN: 978-3-540-790556. Springer. 